\title{
Response Burden Management for Establishment Surveys at Four National Statistical Institutes
}

\author{
Deirdre Giesen ${ }^{1}$, Mario Vella ${ }^{2}$, Charles F. Brady, Jr. ${ }^{3}$, Paul Brown ${ }^{4}$, \\ Daniela Ravindra ${ }^{2}$, and Anita Vaasen-Otten ${ }^{1}$
}

\begin{abstract}
Managing response burden is key to ensuring an ongoing and efficient supply of fit-forpurpose data. While statistical organizations use multi-faceted approaches to achieve this, response burden management has become an essential element of the strategy used by the U.S. Census Bureau, Statistics New Zealand, Statistics Canada, and Statistics Netherlands. Working in collaboration with respondents, with internal resources dedicated to provide customized approaches for large respondents and with other stakeholders (constituency representatives, associations, etc.) response burden management endeavors to minimize burden and educate stakeholders on the benefit of official statistics. The role continues to evolve with important initiatives regarding the compilation of burden metrics, improvements to existing tracking tools, and an expanded communication role.
\end{abstract}

Key words: Actual burden; perceived burden; official statistics; respondent advocate.

\section{Introduction}

Meeting the ever-increasing demand for newer, better, and quicker statistics is an ongoing challenge for National Statistical Institutes (hereafter: NSIs). Part of this challenge is managing the response burden, especially for data provided by businesses. Business reporting to NSIs is often mandatory. Larger businesses typically have to report data for many different surveys and have to do so on a regular basis. There are opportunity costs for businesses: time spent on reporting to NSIs is time forfeited from the core business processes. From that point of view, statistical reporting is a cost for businesses and can be

1 Statistics Netherlands, PO Box 4481, 6401 CZ Heerlen, the Netherlands. Emails: d.giesen@cbs.nl and amvj.vaasen-otten@cbs.nl

${ }^{2}$ Statistics Canada, 170 Tunney’s Pasture Driveway, Ottawa, K1A 0T6 Ontario, Canada. Emails: mario.vella@ canada.ca and daniela.ravindra@canada.ca

3 U.S. Census Bureau, 4600 Silver Hill Road, Washington, DC 20233, U.S.A. Email: charles.f.brady@census.gov

${ }^{4}$ Statistics New Zealand, 8 Gilmer Terrace, PO Box 2922, Wellington 6011, New Zealand. Email: paul.brown1@stats.govt.nz

Disclaimer and acknowledgments: The views expressed in this article are those of the authors and do not necessarily reflect policies of their employers. The authors would like to thank Ger Snijkers, Statistics Netherlands, for recognizing the importance and the relevance of this topic for National Statistical Institutes, and then bringing together the necessary elements for a productive exchange in an invited session at the Fifth International Conference of Establishment Surveys, culminating in this article. Gratitude is also owed to Norbert Rainer, now retired from Statistics Austria, for acting as a discussant at this invited session and synthesizing the common elements and challenges of the contributing country authors. Finally, we are grateful to the anonymous reviewers and the Associate Editor for their meticulous and valuable comments and suggestions that helped us to improve this article. 
cause for complaints. Several studies indicate that a too high level of response burden may also affect the quality and timeliness of the collected data (e.g., Hedlin et al. 2005; Bavdaž 2010; Giesen 2012; Jones 2012; Lorenc et al. 2013; and Berglund et al. 2013). However, it must be noted that more research is needed into the relationship between burden and response behavior, as for example McCarthy et al. (2006) did not find a negative effect of accumulated burden on cooperation. Finally, as pointed out by Bavdaž et al. (2015), response burden can affect the strategic relationship between NSIs and the business world.

Governments, international organizations, and NSIs are well aware of the risks of imposing too much burden, and response burden management is part of several international and national guidelines. For example, the Fifth Principle of the United Nations' Fundamental Principles of Official Statistics (United Nations 2014) states that data sources should be selected "with regard to quality, timeliness, costs and the burden on respondents". The Ninth Principle of the European Statistics Code of Practice specifies: "The statistical authority monitors the response burden and sets targets for its reduction over time" (European Commission 2011). Response burden is also part of the overall regulatory burden and subject of policies aimed at managing burden, for example, the U.S. Paperwork Reduction Act (1995), the Commonwealth of Australia (2014) or the EU Regulatory Fitness and Performance Programme (European Commission 2015a, 2015b).

For NSIs, response burden management will ensure that short-term data needs are met, encourage long-term respondent collaboration and drive the statistical organization to explore alternative data sources and estimation methods. Achieving these goals is far from trivial, as the day-to-day decision-making at NSIs is driven by the aim of producing and publishing relevant data. In an increasingly customer-oriented world, survey managers may tend to be more sympathetic to the demands of data users than to the needs of data suppliers. Furthermore, the response burden experienced by businesses can be affected by many different types of experiences with an NSI. These may involve various surveys, various types of contacts about these surveys (e.g., contacting the NSI to require a new password, or being called with questions about data provided) as well as contacts that businesses have with NSIs in their role as a data users (Lorenc et al. 2012).

In their study of the practices of measuring and reducing establishment response burden by NSIs, Bavdaž et al. $(2015,572)$ conclude: “. . . for successful management of response burden different disciplines within an NSI should work together; at least experts from statistical units, methodology, data collection and communication should be involved. A central place for measuring and managing response burden seems an efficient way to facilitate and to stimulate such cooperation throughout NSIs." At some NSIs, response burden management has evolved into such a coordinated NSI-wide approach. This article presents the mechanisms put in place for managing response burden in establishment surveys by four NSIs: the U.S. Census Bureau, Statistics New Zealand, Statistics Canada, and Statistics Netherlands. These NSIs have created positions to facilitate response burden management. The U.S. Census Bureau and Statistics New Zealand have a Respondent Advocate, Statistics Canada has an Ombudsman for Businesses, and Statistics Netherlands has a Response Burden Coordinator. Their tasks can include: measurement of response burden, internal coordination of response burden management, building a relationship with business associations, and resolution of complaints on an individual level. This article will highlight the many common processes, as well as some country-specific ones. 
It provides an overview of current best practices and experiences regarding establishment response burden management at these four NSIs.

The following section provides an overview of the governance structures for establishment response burden management at the U.S. Census Bureau, Statistics New Zealand, Statistics Canada, and Statistics Netherlands. Section 3 focuses on the concept of response burden and gives an overview of the practices in measuring and monitoring burden at the four NSIs mentioned above. Section 4 highlights some of the main burden reduction strategies of these NSIs, and we conclude in Section 5 with an overall discussion on response burden management.

\section{Governance Structures for Response Burden Management}

The U.S. Paperwork Reduction Act (1995) requires all federally sponsored data collections to obtain approval from the Office of Management and Budget. The purpose of this is to ensure that federal agencies do not overburden the public. For this approval process, the U.S. Census Bureau is, among other things, required to document the burden of the collection. Within the U.S. Census Bureau, the Economic Directorate has a threepronged approach to respondent-interfacing activities that form the overall structure for response burden management: Outreach and Promotion, Contact Strategies, and Respondent Advocacy. The Account Manager program, a component of the Outreach and Promotion effort, works to reduce burden by providing direct customer service to the nation's largest businesses. Indirect outreach, communicated through "trusted voices" such as trade associations and chambers of commerce, complements the Account Manager program by providing communications to small and medium-sized respondents. Work is integrated into the design of a robust Contact and Outreach strategy for the Bureau's survey and economic census activity. The newly created Respondent Advocate position represents the interests of respondents to the Census Bureau's economic surveys and censuses. A primary role of the Respondent Advocate is to identify areas of concern, based upon resonating themes gleaned from respondent interactions across the Directorate.

In New Zealand, legislation requires the approval of the Minister of Statistics for substantive changes to an existing survey or to start a new one. The purpose is to provide assurance that the compliance burden imposed by the survey is reasonable and justified by the value of the information generated. A Respondent Advocate role was established in Statistics New Zealand in 2008 to ensure more effective representation of the interests of survey respondents. The role reports directly to the Government Statistician and the holder acts independently, having no line management responsibilities that entail either survey management or statistical production. Respondent advocacy sits within a broader operational strategy and program of respondent management that seeks to ensure an ongoing and efficient supply of fit-for-purpose data, whilst maintaining the legitimacy, credibility and trust needed to ensure the sustainability of both the collection and use of data.

When the Respondent Advocate position was established at Statistics New Zealand, it was primarily envisaged as a reactive role, providing a ready response to address respondent-related issues, particularly complaints that could not or had not been managed effectively within the Collection Operations systems and processes. However, it also had 
an active element, promoting (particularly to data suppliers) the purpose and benefits of official statistics, recognising that the supply of data is rooted in both perception and knowledge of its uses and benefits. Over time, Respondent Advocates have sought to make the role more active by reviewing business strategies and initiatives that impact on respondents, championing policies and programs that impact on respondents, and mentoring staff involved in managing respondent issues. The Respondent Advocate has instituted an efficient standard work process that factors survey respondent interests into the early stages of the survey (re)design process. The Respondent Advocate provides advice to the Government Statistician on the trade-off between the information value and compliance burden of any proposal. This means that at the start of the development process, business managers must consult with the Respondent Advocate about the need to seek formal approval. If deemed necessary, the manager submits a business case addressing the measures that are being taken in the design to minimise burden and enhance respondent experience, and providing assurance that the expected burden will be within reasonable bounds. This provides the basis for seeking an approval-in-principle decision from the Minister.

At Statistics Canada, two committees hold ultimate responsibility with regard to respondent burden. The Business Response Management Committee (BRMC) chaired by the Assistant Chief Statistician, Economic Statistics Field, provides strategic leadership to minimize respondent burden on businesses associated with Statistics Canada's statistics programs. It is responsible for implementing and overseeing strategic initiatives aimed at reducing response burden on businesses. Its subcommittee scrutinizes and exercises due diligence, before approving any planned increases in burden resulting from new Statistics Canada surveys or modifications to existing surveys targeting businesses. The approval process involves two distinct phases: the first covers the rationale of the request, proposed strategy and general timelines, while the second takes place when the impacts and risks on response burden are better known.

The Ombudsman for Businesses functions as the secretary of the BRMC and is the first point of contact. Statistics Canada has nearly 20 years of experience with the position of Ombudsman for Businesses. The role has evolved from emphasis on respondent relations, which remains a core function, to an active role in response burden management, reduction, monitoring and reporting.

Statistics Netherlands has actively worked on managing response burden in business surveys since the early 1990s. An important factor in the development of response burden management was the Statistics Netherlands Act of 20 November 2003 that declared both the right and the obligation to use register data for the production of statistics. Only if data are not available in registers is data collection allowed. Furthermore, the Act states that the ensuing burden should be minimized. Statistics Netherlands reports annually on a number of key performance indicators to the Minister of Economic Affairs. One of the indicators concerns the total burden (in euros) caused by mandatory statistics. The target and realized values are published in the annual report. Another key performance indicator related to response burden is the general satisfaction with Statistics Netherlands among (non)respondents to business surveys.

Statistics Netherlands established the formal position of response burden coordinator in 2014 to further streamline and stimulate response burden management. The response 
burden coordinator is secretary to the Programme Steering Group on Respondents. This steering group consists of senior managers of all divisions implicated in producing economic statistics and acts as a forum to discuss all main respondent-related policies, best practices and lessons learned, as well as to monitor respondent-related projects. Statistics Netherlands has integrated business respondents' perspectives with the so-called Respondents' Advisory Board. This board consists of four chairs of trade organizations and four directors of companies. The board advises on all business respondent-related topics and keeps Statistics Netherlands sensitive to the respondent view on respondentrelated processes and proposed innovations.

\section{Measuring and Monitoring Response Burden}

\subsection{Concept and Measurement}

It seems evident that response burden metrics are the basis of sound response burden management. However, it has been established that there are large differences between (and also within) NSIs in how the concept of response burden is defined, measured and monitored (Rainer 2008; Haraldsen et al. 2013; Bavdaž et al. 2015). These differences are related to different conceptualizations of burden and different motivations for monitoring burden.

Willeboordse (1997) describes how the concept of response burden in statistics can be defined by four dimensions: 1) objective or subjective - measurement of actual costs of survey participation or of the burden as perceived by the respondent, 2) gross or net depending on whether the benefits of the statistics produced for the reporting unit are taken into account (net) or not (gross); 3) imposed or accepted - regarding the difference between all required data from all sampled units, versus the data actually provided by the responding units; 4) maximalistic or minimalistic - depending on which activities are included in the estimation of the burden (e.g., only time needed for completing the survey or also time spent replying to follow-up calls, and setting up and maintaining structures for the reporting).

The difference that Willeboordse (1997) indicated between objective and subjective burden is often discussed in terms of actual burden (i.e., the time and/or money spent on statistical reporting) and perceived burden (business respondents' perception of their experience with the survey request). Both types of burden seem to be relevant in understanding the functioning of survey instruments and response behavior (e.g., Hedlin et al. 2005; Dale and Haraldsen 2007; Giesen 2012; Berglund et al. 2013).

Haraldsen et al. (2013) distinguish different perspectives on the monitoring and measurement of burden that are related to different reasons for monitoring. Typically, for political reasons (e.g., policies on regulatory burden), the total actual burden placed on all businesses during a specific period, is monitored. For managing burden placed on individual businesses, both actual and perceived burden on the business level may be monitored. Actual burden on the business level is also needed for analyses of burden, including but not limited to, the spread of burden over a specific period. Data on burden on the business level allows, for example, analyses of average costs of regulatory compliance per employee and costs as a share of business revenue by size of businesses and sector (see also Seens 2013). Finally, both perceived and actual burden may be monitored from the 
perspective of the surveying organization. The availability of data on burden imposed by each survey allows identification of aspects of the design that could be improved or that potentially could affect the quality of survey responses.

In this section we will describe the monitoring of actual burden, perceived burden, and complaints in the four NSIs.

\subsection{Actual Burden Measurement}

Many NSIs monitor actual response burden (i.e., time and/or money spent by businesses to comply with the survey request), but with variations in the methodology used (Bavdaž et al. 2015). We also see these variations for the four NSIs whose response burden management is described in this article. The U.S. Census Bureau only assesses actual response burden at the survey level. Estimates of actual burden, as required by the Office of Management and Budget, are the only formal documentation of response burden. Response burden estimates are based on several resources: periodic formal, cognitive testing with potential respondents and, occasionally, with Census Bureau staff; conversations with respondents; consideration of additional questions added to a survey; comparing a reporting instrument with others that are similar in length and content; historical comparison - comparing with previously fielded versions of the same instrument. The burden of collection is expressed to the respondent through the "Burden Estimate Statement", which is included in the initial letter to respondents and on the instrument itself (both paper and electronic). This statement informs the respondent of the average expected time burden of the collection and invites the respondent to comment on the accuracy of that estimate.

Statistics New Zealand, Statistics Canada, and Statistics Netherlands calculate various indicators of actual response burden to determine trends, as well as the impact of mitigating strategies. All three statistical agencies track the accepted actual response burden (also called survey load) while Statistics Canada also measures the imposed burden (or 'potential burden'). Different indicators are used to measure and monitor the load: total and mean time taken to respond and index of reporting load. These indicators have shown a decrease in response burden over time, which is testimony to the successful implementation of various mitigation strategies.

In New Zealand, response burden is measured in terms of the 'time taken to complete the survey', as reported by individual respondents furnishing self-completion forms. For interviewer-administered and online surveys, system data are used. Figure 1 shows that in New Zealand, response burden has declined significantly over the past eight years, as the survey program has been progressively rationalized and more use of administrative data has been made. The administrative data 'dividend' is now expected to level out, as most of the easy gains have been made. The five-yearly peaks in total burden reflect the impact of an Agricultural census. In intervening years, a sample survey is conducted. Figure 1 refers to the aggregate burden across the surveyed population. While this provides a useful indication of the impact of changes in survey design and infrastructure, it does not in itself show how burden is distributed within the survey population. The most critical measure from a respondent perspective is the total burden on them individually. Statistics New Zealand also calculates the number of surveys in which businesses are included. This 


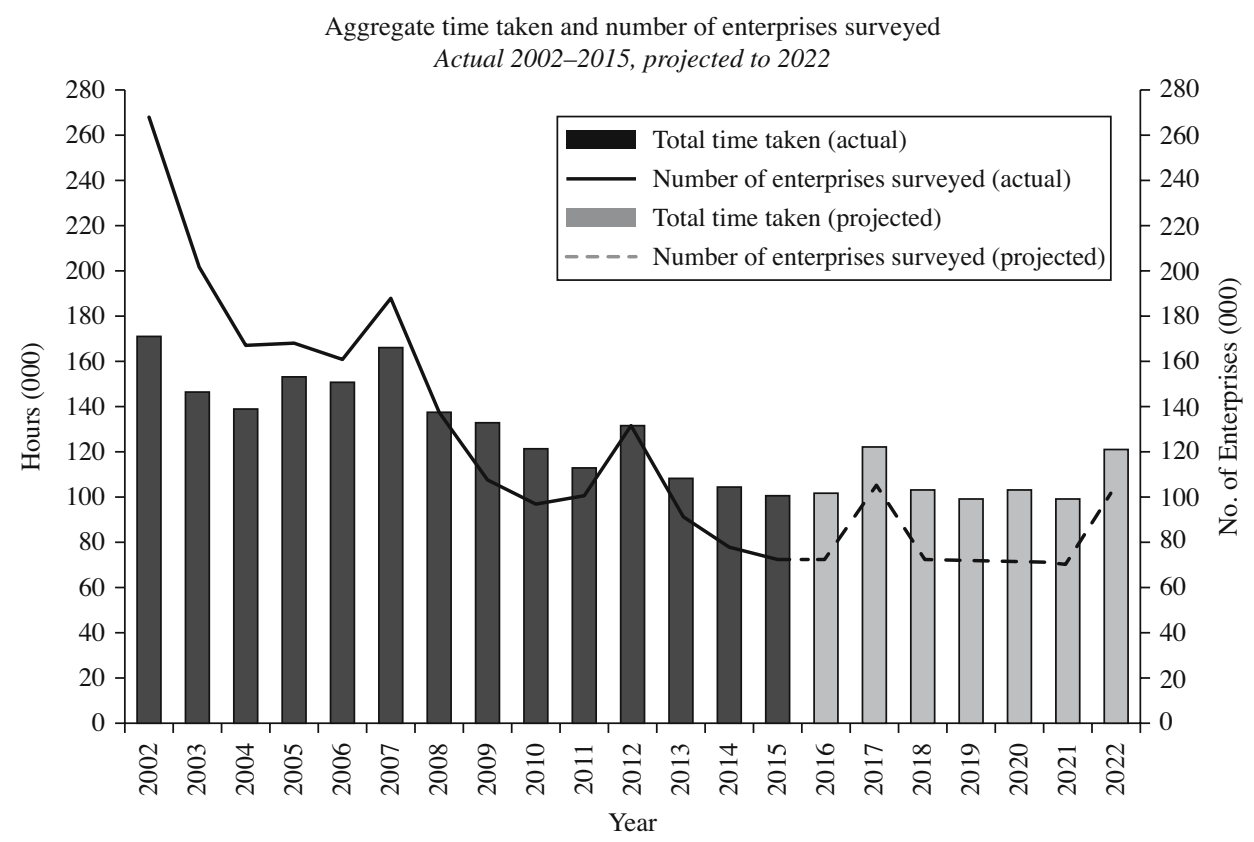

Fig. 1. Statistics New Zealand: actual and projected response burden 2002-2022. Source: Statistics NZ.

allows a 'hotspot' review that identifies businesses whose total survey load exceeds specified thresholds and provides avenues for mitigation strategies. Survey relief is granted to those businesses, conditional on the impact of their absence on the statistical output being manageable.

At Statistics Canada, the Ombudsman for Businesses annually reports 'compliance costs' for Statistics Canada's business surveys - that is, the costs (or response burden) in hours associated with businesses completing Statistics Canada surveys. The report focuses on measuring 'potential costs' associated with each survey. The potential costs do not take into account response rates. They are designed to measure the demand Statistics Canada places on businesses, regardless of whether they chose to accept that demand by completing surveys. All business surveys administered by Statistics Canada possess a standard question asking the respondent to report the time required to respond. Statistics Canada maintains an index of response burden hours from 1991 to the present with an average performance target of 60 minutes or less per business annually. The trend depicted in Figure 2 shows how the significant expansion of the economic statistics program in the late 1990s caused a spike in burden. However, the increased use of administrative data, the establishment of a single point of contact for large and complex enterprises through the Enterprise Portfolio Manager (EPM) program and the greater unification, harmonization and integration of statistical programs led to a continuous decrease in burden over the last 15 years.

Statistics Netherlands estimates time needed for reporting based on respondents' answers to a question about the total time spent by the organization to comply with the data request. This question is periodically added to questionnaires. A total response burden per 


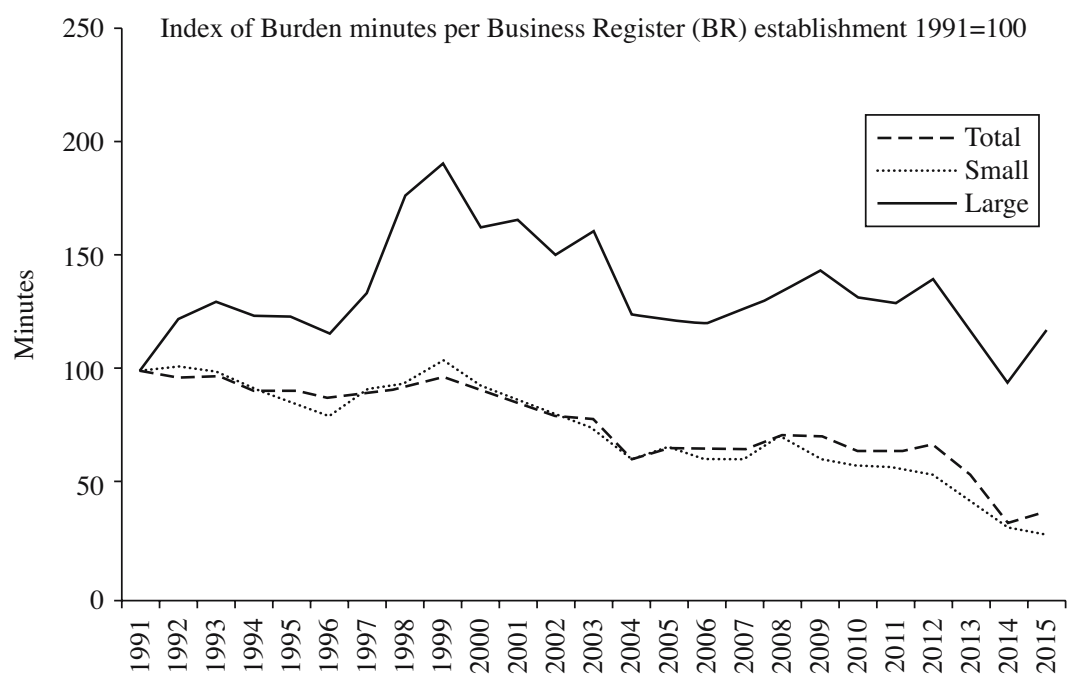

Fig. 2. Statistics Canada: index of reporting load minutes per establishment $(1991=100)$.

survey is calculated both in euros and minutes based on this mean time in minutes, the total number of returned questionnaires and an average wage rate. As shown in Figure 3, response burden (as expressed in euros) has decreased by about $70 \%$ during the period 1994-2014. Important drivers behind this burden reduction were the increased use of administrative data, the use of advanced statistical methodology and the innovations in electronic data collection (e.g., facilitating upload of data in a standard record layout and the use of web scraping to collect price information).

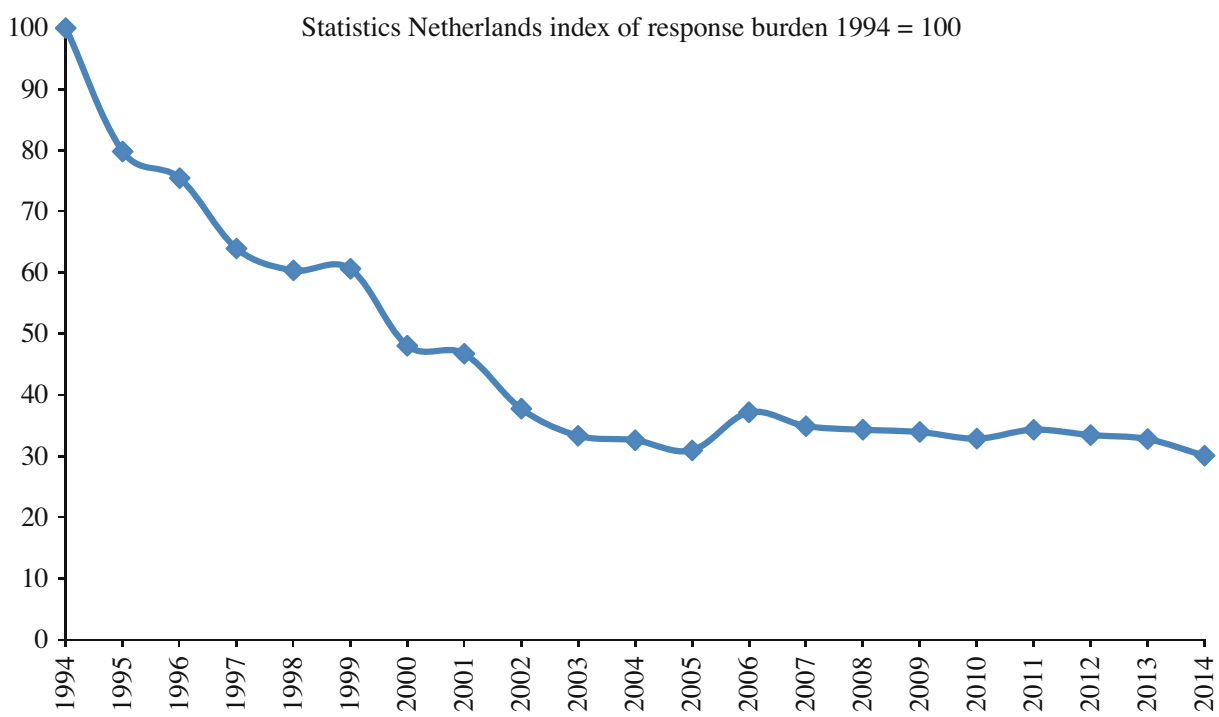

Fig. 3. Statistics Netherlands: index of response burden (as measured in euros) 1994-2014. 


\section{Perceived Burden}

The study by Bavdaž et al. (2015) showed that NSIs monitor perceived burden, that is, the respondents' perception of their experience with the survey request, less frequently than actual burden. For the four NSIs discussed here, only Statistics Netherlands has some systematic measurement of aspects of perceived burden. This has been done since 2007 as part of the annual Customer Satisfaction Survey. For this telephone survey, both respondents and nonrespondents to the Survey on International Trade in Goods (hereafter: ITG) are interviewed about their experience with the survey and Statistics Netherlands. The survey of ITG accounts for half of Statistics Netherlands' total actual response burden. Respondents to the ITG are asked whether they thought answering the questions was 'easy', 'neither easy, nor difficult' or 'difficult' and whether answering the questions was 'much work', 'neither much, nor little work' or 'little work'. These measurements of perceived burden are based on the recommendations in the Eurostat Handbook for Monitoring and Evaluating Business Survey Response Burden (Dale and Haraldsen 2007). Other indicators from this survey, measured for both respondents and nonrespondents to the ITG, are also relevant for monitoring perceived burden. For example, one item measures whether Statistics Netherlands explains well enough why data are collected. Also, respondents are requested to provide an overall rating of satisfaction with the agency. The results did not provide any indication of clear trends in the period 2007-2015. There have been fluctuations, but these were always difficult to explain by specific actions taken.

\subsection{Complaints}

Monitoring the number and types of complaints received from respondents is another important indicator of actual and perceived burden and offers insights into possibilities for burden reduction. In the United States, the Respondent Advocate for economic surveys is positioned as a centralized resource for respondent complaints received across the U.S. Census Bureau. Respondents and their representatives send complaints to a variety of offices within the Census Bureau. Those wishing to escalate matters immediately may send complaints directly to offices of the Census Bureau's Director and the Associate Director for Economic Programs. Others contact subject matter areas responsible for specific surveys or reach the Census Bureau's call center. Complaints come not only from respondents, but also from entities such as U.S. congressional offices.

The Respondent Advocate, once notified of a complaint, seeks guidance from staff across the Economic Directorate who may be able to help craft a response. This often entails research regarding the number of surveys a respondent is mailed, by accessing a company calendar and a list of a company's surveys maintained in an internal database, to better understand the burden placed upon a respondent. Solutions include calling the company directly to explain the importance of response. At times, an appropriate action is to develop an alternative, less burdensome reporting arrangement.

In New Zealand, although the proportion of respondents who comply has not changed much, those who resist are pushing back harder. Statistics New Zealand receives around 500 complaints annually, which are investigated and monitored. This is generally managed within the Collections Operations group and two designated full-time employees undertake the bulk of the investigations and much of the relationship management follow-up. 
The Respondent Advocate handles the more difficult and complex cases, particularly those that have not been remedied through the Collection Operations processes. These typically require a degree of tailored relationship management beyond that provided through the standard relationship management services. In dealing with complaints from individual respondents, the Respondent Advocate is able to provide gravitas to a response that might otherwise be considered 'stock and trade', to offer a specific remedy tailored to the circumstances of the respondent, and to recommend improvements to the standard processes and procedures where investigation of the complaint has pointed to shortcomings. The Respondent Advocate at Statistics New Zealand is also in a position to connect more directly the supply of data to the purpose and benefits of the resultant statistical products. This is frequently a critical factor in persuading respondents who are very reluctant or who have initially refused to comply. Analysis of complaint types (Figure 4) indicates that over three quarters of them relate to the conditions under which the surveys are conducted, for example burden, interviewer/process, inconvenience and extension or payment. These are issues that are, to some extent, remediable.

At Statistics Canada, most complaints received generally fall into one of the two following categories:

1. Data collection: official languages not respected, Business Register information, collection methods and agreements, privacy, confidentiality and legal issues, ethics.

2. Response burden: request for relief or exclusion, too many surveys, completing the survey takes too much time, too costly, lack of relevance, or lack of compensation or remuneration.

Complaints about data collection usually involve technical problems encountered by the respondent in delivering data to Statistics Canada using various methods of transmission. Much data collection is done electronically using electronic questionnaires, where access codes are provided by email to respondents for uploading data to secure government infrastructure. Data collection complaints are distinguished from complaints of response burden, as the latter are more likely to lead to a nonresponse or chronic refusal. Complaints

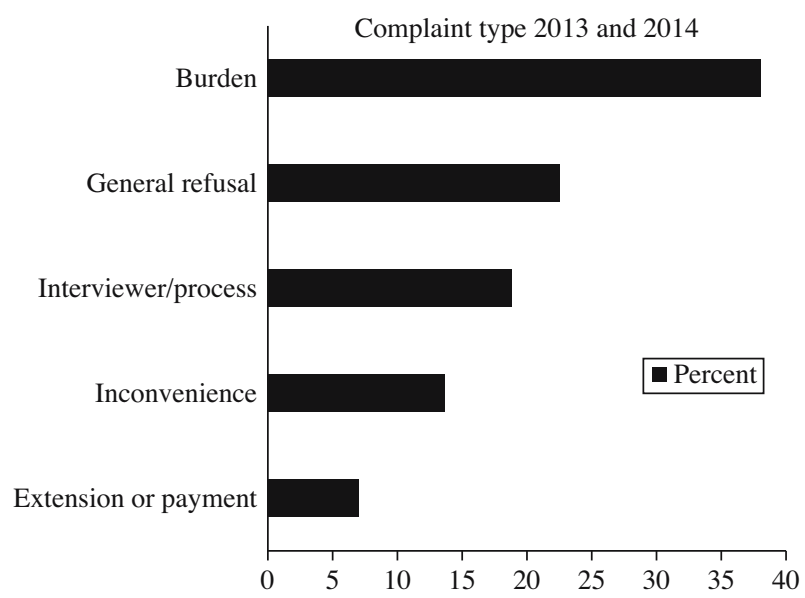

Fig. 4. Statistics New Zealand: complaint type. Source: Statistics New Zealand. 
about burden are often triggered by monthly surveys nearing the end of a collection cycle after a sequence of follow-ups and reminders have not resulted in response. Only verifiable complaints are handled. Those relating to single surveys or multiple surveys within one program area are directed by the Ombudsman for Businesses to the appropriate area for a response by the director of the division. In cases of multiple surveys from different areas, the Ombudsman's office negotiates a solution with the impacted areas, which is then communicated to the respondent by the Ombudsman for Businesses or a member of his/her staff. Service standards have been developed for the resolution process (e.g., acknowledging the complaint and providing a solution within a given period of time). All complaints are documented, dispatched and resolved using the Client Response Management System (CRMS), which is an Oracle PeopleSoft database with adapted functionality for respondent relations. The CRMS is used by more than 500 employees at Statistics Canada. About 20\% of CRMS users use the tool to document business respondent relationship requests.

Figure 5 illustrates the industry distribution of Ombudsman cases. In 2015, businesses classified as manufacturers represented about 32 percent of the Ombudsman's case files. The response burden in Canada is most pronounced in manufacturing. These businesses can be asked for information relating to labor, finances and production and are more likely to be multi-establishment and involved in cross-border trade. Since manufacturing, as an activity, touches a number of areas of statistical interest, such as the disposition and use of energy in the transformation of inputs to outputs, innovation and investment, there are 24 different questionnaire types that can potentially be sent to manufacturers.

Statistics Canada has put in place different processes of managing response burden depending on business size and complexity. Table 1 illustrates this relationship: it is not

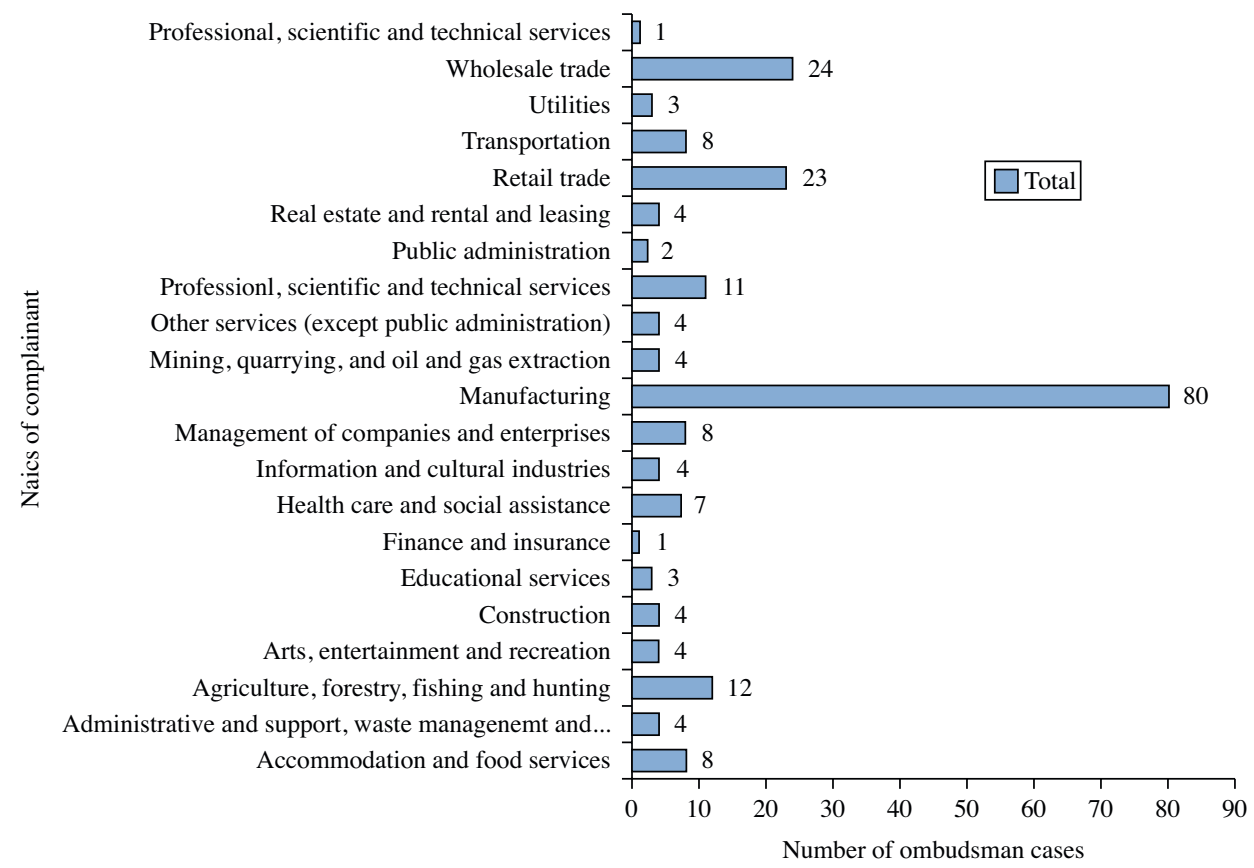

Fig. 5. Statistics Canada: number of Ombudsman cases by industry 2015. 


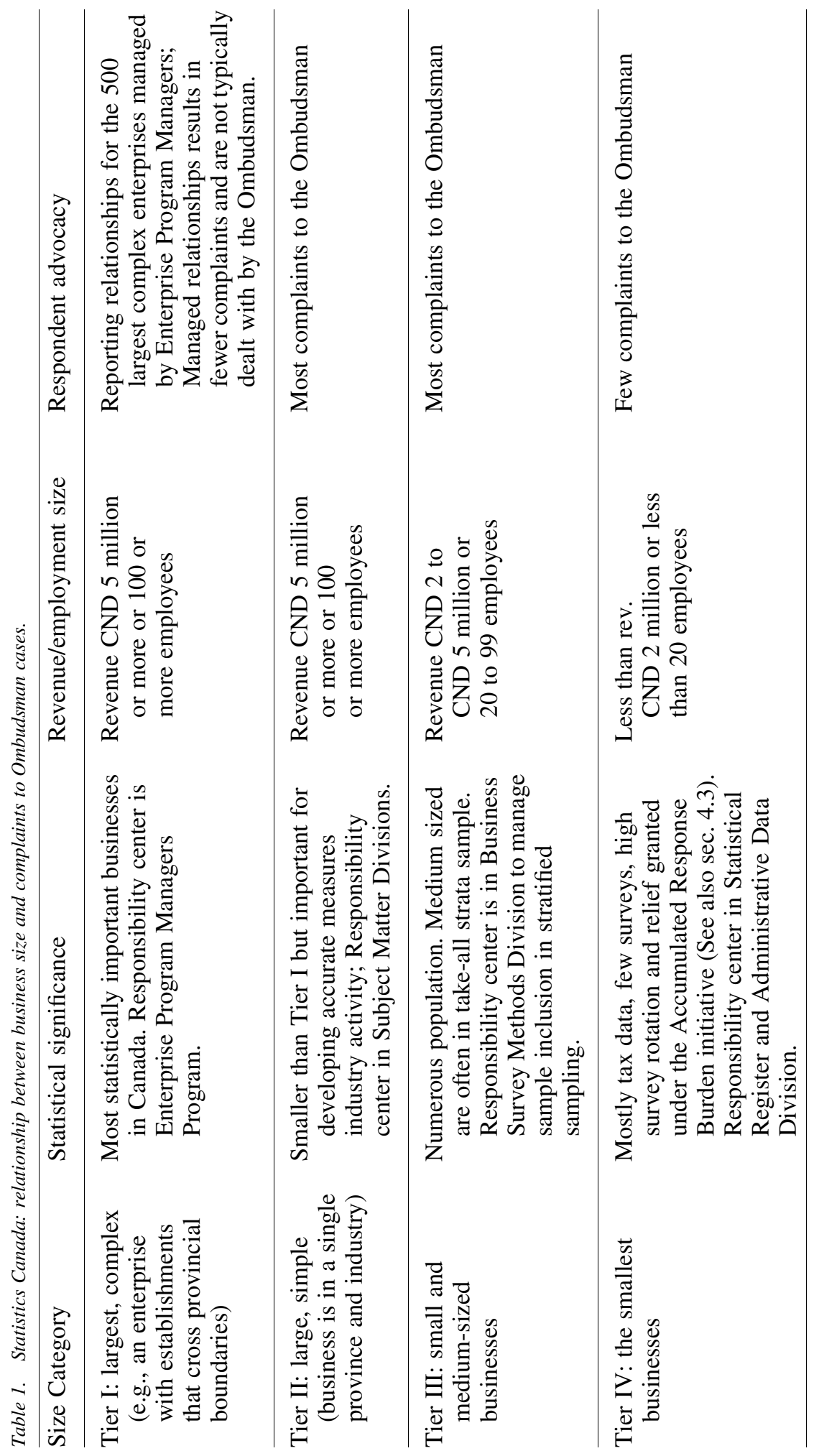


surprising that most complaints received by the Ombudsman for Businesses are from large, but not complex, businesses and medium-sized businesses. The vast majority of small businesses are not sampled, while the very large and complex businesses are handled through customized approaches by the Enterprise Portfolio Manager (EPM) program. The distinguishing feature between Tier 1 and Tier 2 businesses is not one of size but one of complexity. Tier 1 businesses operate in more than one Canadian province or territory and may operate in more than one industry. Statistics Canada is concerned with coherence between statistical enterprises and their establishments, as well as interprovincial flows. A combination of size and complexity are important criteria to determine a business' admissibility into the EPM program. It is rare that the Ombudsman for Businesses receives complaints from businesses covered under the EPM program. The program facilitates respondent relations and custom-tailored reporting to Statistics Canada for these statistically important businesses.

At Statistics Netherlands, respondent complaints are registered by the communication unit in the centralized division of data collection. Complaints are reported to the management of the data collection division on a regular basis (and of course immediately if needed). The response burden coordinator receives quarterly reports. Annual reports about the number and types of complaints are also discussed with the Program Steering Group on respondents and the Respondent Advisory Board.

\section{Strategies to Manage Burden}

\subsection{Sources of Response Burden}

The Total Business Survey Burden Model (Haraldsen et al. 2013) describes different sources and effects of response burden and links these to the data collection process. The model describes how burden originates from stakeholders and the survey organization, as they define the survey requirements. The survey requirements, in turn, affect the survey design. The model distinguishes three main aspects of the survey design that affect response burden: the sample, the instrument and the communication strategy. Response burden is created in the interaction of the respondent with the survey instrument. This interaction is affected by the response environment in which it takes place, including factors such as data availability, and the motivation and capacity of the respondent. The many and heterogeneous factors that affect response burden as described in this model indicate that response burden management will involve many and heterogeneous aspects of the survey organization. It is beyond the scope of this paper to give a complete overview of all response burden management strategies used over time at the four NSIs discussed in this paper. In this section, we will highlight some of the common strategies used by the four NSIs and the projects they are currently focusing on: 1) reduction of data collection by using alternative data sources; 2) mitigating burden at the business level; 3) communication strategies, and 4) instrument design.

\subsection{Alternative Data Sources}

A key to reducing burden is to identify alternative-to-survey data that may be used to satisfy statistical needs. Reuse of data - also from other organizations and use of big 
data - presents NSIs with new opportunities and challenges. These involve, among others reengineering business survey processes to make better use of the capabilities to integrate data from different sources. Statistics Canada has created an Administrative Data Division whose mandate is to identify and secure agreements for the use of data sets that may exist from mostly government departments in order to avoid the need to survey respondents or reduce the length of surveys. In the Netherlands, a system of base registers is developed to facilitate the reuse of data. The aim of this system is to facilitate the principle of single filing of information by individuals, companies, and institutions and the multiple use of this information by government institutions. The changes in the base registers facilitate broader use of administrative data by Statistics Netherlands (e.g., Brummelen and Vaasen-Otten 2010; Zwijnenburg 2012).

In Canada and the Netherlands, further implementation and promotion of the use of Standard Business Reporting (SBR, a national standard for digital reporting of business information to the government) is being explored as a promising avenue for further burden reduction (Born 2016; Buiten et al. 2016). Statistics Netherlands is also investigating the feasibility of promoting the use of SBR for statistical reporting by offering relevant statistical output.

\subsection{Mitigating Burden at the Business Level}

The Respondent Advocate of the U.S. Census Bureau works with research and methodology staff, subject matter staff, and operation area staff to determine the best way to address and implement any changes required. Part of this involves revisiting sampling procedures to reduce burden on small and medium-size businesses.

Statistics New Zealand, Statistics Canada and Statistics Netherlands stage business surveys from a centralized system or business registry. In New Zealand, the centralized system provides a respondent-centric view of burden, facilitating mitigation strategies targeted to individual respondents. Minimization of business survey response burden is provided through a 'hotspot' review that identifies businesses whose total burden exceeds specified thresholds. Survey relief is granted to those businesses, conditional on the impact of their absence on the statistical output being manageable. This may mean that the impact on the reliability of the statistical outputs is acceptable, or imputation provides a suitable alternative.

At Statistics Canada, the centralized system is used to reduce excessive accumulation of response burden on small businesses with minimal impact on the quality of the statistical outputs. This so-called 'Accumulated Response Burden Initiative' is mostly targeted at the Tier 3 and 4 businesses described in Table 1. The accumulated response burden adds the time a respondent business needs to take to respond to all questionnaires sent by Statistics Canada over a three-year period. Survey relief is provided for small businesses once a prespecified level of burden hours for that business has been met. Identified businesses are excluded from data collection and are treated as nonresponse. The centralized business register has a response module that contains knowledge of basic information relating to the surveys that the business receives, and response history. It also permits an evaluation to avoid duplication in survey information. 
In the Netherlands, the sampling for 13 different business surveys is currently done via a centralized system. This system allows the coordination of sampling for several surveys at the same time. The objective of this system is a more even distribution of the response burden over businesses over time. Methodology has recently been developed to further use this system, combining both panel and non-panel surveys (Smeets and Boonstra 2017). Also, the system for measuring actual response burden has recently been improved in the Netherlands in order to allow assessment of burden on the level of the business unit (previously, only aggregate analyses of total annual burden were possible). Analyses of these data will help to detect any 'hot spots' in the response burden.

\subsection{Communication Strategies}

As discussed by Snijkers and Jones (2013), business survey communication involves many aspects, varying from the specific communications needed for data collection to corporate strategies to influence the attitude toward the legitimacy of official statistics. Giesen and Snijkers (2011) argue that NSI communication affects response burden through the actual and perceived costs and benefits of a survey request. For example, providing a centralized helpdesk may reduce the actual costs for respondents to comply with a survey request, and promoting the use of official statistics may increase the perceived benefits of response.

A common theme from the experiences of the four NSIs is to conduct respondent outreach and interact with respondents in a unified and coordinated way to assure a cohesive and shared method of coordinating response. The NSIs employ enhanced and improved multi-faceted communication strategies. In all four statistical organizations, customized solutions for the large and complex enterprises is part of their response burden management. They recognize the disproportionate burden put on these respondents and the importance of their data to statistical estimates. Dedicated units have been put in place to provide individual services to the top respondents (varying from top 100 in New Zealand to top 1,648 in the United States). Typically, these specialized units develop relationships with the data providers, create customized response plans and assist data providers in completing questionnaires.

At the U.S. Census Bureau, the Account Manager Program assesses large companies across directorate programs and finds ways to reduce total burden for data providers. The Program was previously employed for the five-year Economic Census and is now being introduced for more frequently occurring surveys.

In Canada, the Enterprise Program Managers (the equivalent of account managers) are also responsible for maintaining the company structure up-to-date in the Business Register and they negotiate reporting arrangements that minimize response burden.

At Statistics New Zealand, the Respondent Advocate, based on an analysis of complaints, defined another important segment besides the top 100 businesses. This group can be labeled as 'statistically important but with low compliance capability'. While the group does not contain a large number of businesses, they tend to be serial complainants and therefore worthy of some investment. The Respondent Advocate was successful in persuading the Data Collections group to extend the scope of the Key Account Unit to accommodate this segment. This entails some one-on-one consultancy to identify options 
to manage the burden. Examples of improvement measures include identifying more efficient means of furnishing the required data and providing an advance calendar of survey requests. The experience in New Zealand is that the personal attention pays dividends and gives a strong signal to the respondents, and others they are connected with, that the government agency has a human face and listens to them.

At Statistics Netherlands, account managers also analyze the micro data and deliver it to the statistical departments. This results in solving a number of data inconsistencies for these enterprise groups, therefore improving the quality of the business statistics and that of the national accounts. It was found that enterprise groups are generally cooperative and willing to supply the information that is necessary to solve or explain inconsistencies (Vennix 2012). Documenting the analytical process helps ensure that inconsistencies that are solved once will not reoccur.

All four NSIs have respondent relations management systems and are investing in them. These systems, and staff training, facilitate coordinated communication with businesses. Coordination is essential to ensure that best practices are followed and policies related to client services and respondent relations are applied in a consistent manner.

In addition to communication strategies focused directly on data collection, the four NSIs also employ communication strategies to convey the purpose and benefits of official statistics. This is done through information on their respective websites, brochures and in the case of Statistics Canada, also with a video on the how and why of business surveys. Promoting the use and perceived usefulness of statistics also includes developing and maintaining partnerships with stakeholders, such as trade associations and chambers of commerce, to communicate to their constituents the importance and relevance of response to official statistics. The Respondent Advocate of the U.S. Census Bureau also works on enhancing communication with members of the United States Congress and their staff. Respondents often write their congressional representative to ask questions or voice concerns about the economic surveys they receive. A more proactive approach is being taken to engage members of Congress and their staff with meetings and webinars addressing some of these issues. The aim is to educate them about the Census Bureau's programs, so they are equipped to be the first line of communication in addressing constituent needs, while creating increased awareness.

\subsection{Data Collection Instrument Design}

Obviously, the design of the data collection instrument has a large impact on actual and perceived response burden. The four NSIs in this article are well aware of that and have developed strategies to include the respondents' point of view in the instrument design process. For example, the U.S. Census Bureau Respondents' Advocate works with others to identify alternative reporting options that would satisfy response. At Statistics New Zealand, business managers must submit a business case for new or redesigned surveys, presenting the measures that are being taken in the design to minimize burden and enhance respondent experience, and must make sure that expected burden will be within reasonable bounds. Strategies described by Statistics Canada and Statistics Netherlands to incorporate respondents' point of view in data collection design include cognitive testing and focus group testing with respondents, and consultation with trade organizations. 


\section{Discussion}

This article is derived from the contributions of the U.S. Census Bureau, Statistics New Zealand, Statistics Canada, and Statistics Netherlands to an invited session on "Establishing and maintaining a relationship with business" at the Fifth International Conference of Establishment Surveys in June 2016 in Geneva, Switzerland (Brady 2016; Brown 2016; Giesen and Vaasen-Otten 2016; and Vella 2016). It provides an overview of the governance structures and practices of coordinated NSI-wide approaches to response burden management at these four NSIs. Table 2 provides a summary of some of the main characteristics.

The common themes from the experiences of the U.S. Census Bureau Statistics, New Zealand, Statistics Canada, and Statistics Netherlands include respondent burden management in terms of response burden reduction, a continual adaptation to a changing statistical landscape, a focal point for tools, methods and measurement of response burden as well as communication and outreach. These statistical organizations are continually striving for opportunities to further reduce both the actual and the perceived burden, recognizing the various sizes of business, their statistical significance and respondent perceptions about burden. Response burden management revolves around innovations in data collection and investing in the relationship with businesses with effective communications on their role as data providers, as well as education on the value of statistical output for businesses. Several common themes emerged in the discussion at the conference and are universally shared among these NSIs.

Enabler of official Statistics - The experiences and evolution of response burden management is widely viewed as enabling official statistics. First, it is universally shared that data sources should be selected with regard to quality, timeliness, costs, and burden on respondents. Fundamental Principles of Official Statistics acknowledge that official statistics broadly serve general interests, business or research interests. As a social investment, data are made accessible by NSIs to illuminate socioeconomic conditions that permit public understanding of the impact of government policies. In this way, NSIs improve the accountability of governments. NSIs are focused on serving these unique needs. The international standard provides comparability. It also provides credibility for the statistical function and official statistics.

Communicating the benefit of statistics - Businesses can, and do, benefit from official statistics. A common challenge for the four NSIs is increasing respondent awareness of the link between surveys and the resulting aggregate industrial information they provide. Official statistics provide information for their own product or service positioning as well as business intelligence such as industry trends. Education and communication - as part of the response burden management - help to convey relevance of the statistical function to respondents. NSIs have strategies and are continually exploring new ones to reach out to industry associations and trade organizations to seek support for statistical participation, and also to support respondent relations. More emphasis is being put on communicating effectively using social media and infographics.

Governance - When seeking the businesses' participation and contribution to official statistics, NSIs exercise strong governance and put in place safeguards to assure confidentiality and transparency in data treatment and eventual dissemination. Several of 


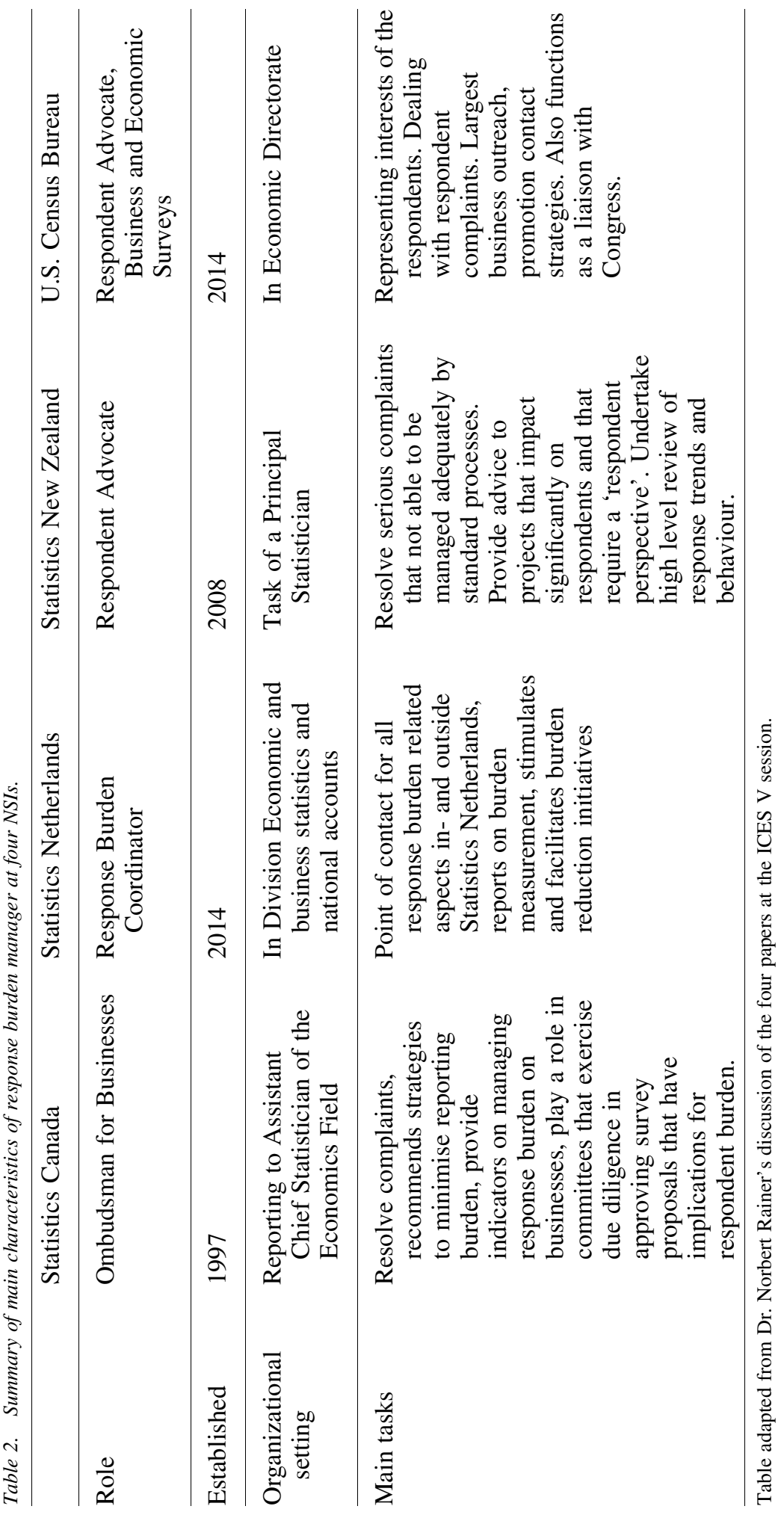


these principles are embodied in response burden management. As a feature of respondent advocacy, impartiality plays a prominent role in balancing respondent concerns with the need to not impede the production of official statistics. Complaints, which most often involve real or perceived excessive burden, may also touch respondent perceptions of privacy, confidentiality, transparency and statistical dissemination. Oversight committees in place in each of the four NSIs ensure that surveys are only conducted when approved and where data cannot be otherwise collected.

Measuring response burden for accountability and minimization - Another aspect of response burden management that aligns with the principles of official statistics is that NSIs must have appropriate measurement and monitoring of response burden. In general, the NSIs have similar techniques to measure actual and potential burden. Measuring perceived burden is not as entrenched across the four NSIs. Response burden is gleaned through questions on completion time on surveys and tracked through the use of business response burden modules attached to business registers. The European Statistics Code of Practice also provides guidance to statistical authorities to monitor response burden and set targets for its reduction over time. It is clear that response burden management is being used as an active partner in the modernization of business statistics.

NSIs use response burden management to continually strive for better ways to minimize response burden and to promote the importance of official statistics. As described in this article, NSIs face very similar challenges and opportunities. Future international collaboration, including the sharing of response burden management, will be an integral feature of the work of NSIs.

\section{References}

Bavdaž, M. 2010. "Sources of Measurement Errors in Business Surveys." Journal of Official Statistics 26: 25-42. Available at: http://www.jos.nu/Articles/abstract. asp? article=260025 (accessed June 2017).

Bavdaž, M., D. Giesen, S. Korenjak Černe, T. Löfgren, and V. Raymond-Blaess. 2015. "Response Burden in Official Business Surveys: Measurement and Reduction Practices of National Statistical Institutes.” Journal of Official Statistics 31: 559-588. Doi: http:// dx.doi.org/10.1515/jos-2015-0035.

Berglund, F., G. Haraldsen, and O. Kleven. 2013. "Causes and Consequences of Actual and Perceived Response Burden Based on Norwegian Data." In Comparative Report on Integration of Case Study Results Related to Response Burden and Motivation in Business Surveys, edited by D. Giesen, M. Bavdaž, and I. Bolko, 29-35. Deliverable 8.1, BLUE-ETS project. Available at: https://www.blue-ets.istat.it/fileadmin/deliverables/ Deliverable8.1.pdf (accessed June 2017).

Born, A. 2016. "Harmonizing Financial Information from Businesses at Statistics Canada." In Proceedings of the Fifth International Conference of Establishment Surveys, June 20-23, 2016. Geneva, Switzerland: American Statistical Association. Available at: http://ww2.amstat.org/meetings/ices/2016/proceedings/146_ices15 Final00226.pdf (accessed June 2017).

Brady, C. 2016. "Respondent Outreach Practices at the U.S. Census Bureau." In Proceedings of the Fifth International Conference of Establishment Surveys, 
June 20-23, 2016. Geneva, Switzerland: American Statistical Association. Available at: http://ww2.amstat.org/meetings/ices/2016/proceedings/095_ices15Abstract00246. pdf (accessed June 2017).

Brown, P. 2016. "Respondent Advocacy at Statistics New Zealand." In Proceedings of the Fifth International Conference of Establishment Surveys, June 20-23, 2016. Geneva, Switzerland: American Statistical Association. Available at: http://ww2.amstat.org/ meetings/ices/2016/proceedings/Paul\%20Brown.pdf (accessed June 2017).

Brummelen, M. van, and A. Vaasen-Otten. 2010. "Changes in the Administrative Sources Used by the Dutch Business Register." Paper presented at the 22nd Meeting of the Wiesbaden Group on Business Registers - International Roundtable on Business Survey Frames. Tallinn, Estonia, 27-30 September 2010. Available at: www.stat.ee/ dokumendid/47281 (accessed June 2017).

Buiten, G., R. van den Boom, M. Roos, and G. Snijkers. 2016. "Issues in Automated Financial Data Collection in the Netherlands.” In Proceedings of the Fifth International Conference of Establishment Surveys, June 20-23, 2016. Geneva, Switzerland: American Statistical Association. Available at: http://ww2.amstat.org/meetings/ices/ 2016/proceedings/148_ices15Final00209.pdf (accessed June 2017).

Commonwealth of Australia. 2014. The Australian Government Guide to Regulation. Department of the Prime Minister and Cabinet. Available at: https://www.cuttingredtape.gov.au/sites/default/files/files/Australian_Government_Guide_to_Regulation.pdf (accessed June 2017).

Dale, T. and G. Haraldsen (Eds.). 2007. Handbook for Monitoring and Evaluating Business Survey Response Burdens. European Commission, Eurostat. Available at: http://ec.europa.eu/eurostat/documents/64157/4374310/12-HANDBOOK-FORMONITORING-AND-EVALUATING-BUSINESS-SURVEY-RESONSE-BURDEN. pdf (accessed June 2017).

European Commission. 2011. European Statistics Code of Practice for the National and Community Statistical Authorities. Adopted by the European Statistical System Committee, September 28, 2011. Available at: http://ec.europa.eu/eurostat/documents/ 3859598/5921861/KS-32-11-955-EN.PDF/5fa1ebc6-90bb-43fa-888f-dde032471e15 (accessed June 2017).

European Commission. 2015a. Better Regulation for Better Results - An EU Agenda. Strasbourg, 19.5.2015 COM(2015) 215 final. Available at: http://ec.europa.eu/ smart-regulation/better_regulation/documents/com_2015_215_en.pdf (accessed June 2017).

European Commission. 2015b. Regulatory Fitness and Performance Programme (REFIT) State of Play and Outlook “REFIT Scoreboard”. Strasbourg, 19.5.2015 SWD(2015) 110 final. Accompanying the document Better Regulation for Better Results - An EU Agenda. Available at: http://ec.europa.eu/smart-regulation/better_regulation/ documents/swd_2015_110_en.pdf (accessed June 2017).

Giesen, D. 2012. "Exploring Causes and Effects of Perceived Response Burden.” In Proceedings of the Fourth International Conference of Establishment Surveys, June 11-14. 2012. Montréal, Canada: American Statistical Association. Available at: https://ww2.amstat.org/meetings/ices/2012/papers/302171.pdf (accessed June 2017). 
Giesen, D. and G. Snijkers. 2011. "Communication Strategies." In Response Burden Measurement and Reduction in Official Business Statistics. A Literature Review of National Statistical Institutes' Practices and Experiences, edited by D. Giesen and V. Raymond-Blaess 50-64. Deliverable 2.1, BLUE-ETS project. Available at: https://www.blue-ets.istat.it/fileadmin/deliverables/Deliverable2.1.pdf (accessed June 2017).

Giesen, D. and A. Vaasen-Otten. 2016. "Response Burden Management for Business Surveys at Statistics Netherlands." In Proceedings of the Fifth International Conference of Establishment Surveys, June 20-23, 2016. Geneva, Switzerland: American Statistical Association. Available at: http://ww2.amstat.org/meetings/ices/2016/ proceedings/096_ices15Final00082.pdf (accessed June 2017).

Haraldsen, G., J. Jones, D. Giesen, and L. Zhang. 2013. "Understanding and Coping with Response Burden." In Designing and Conducting Business Surveys, edited by G. Snijkers, G. Haraldsen, J. Jones, and D. Willimack, 219-251. Wiley: Hoboken, New Jersey. Doi: http://dx.doi.org/10.1002/9781118447895.ch06.

Hedlin, D., T. Dale, G. Haraldsen, and J. Jones. 2005. Developing Methods for Assessing Perceived Response Burden. Research report. Stockholm: Statistics Sweden, Oslo: Statistics Norway, and London: Office for National Statistics. Available at: http://ec. europa.eu/eurostat/documents/64157/4374310/10-DEVELOPING-METHODS-FORASSESSING-PERCEIVED-RESPONSE-BURDEN.pdf/1900efc8-1a07-4482-b3c9be88ee71df3b (accessed June 2017).

Jones, J. 2012. “Response Burden: Introductory Overview Lecture.” In Proceedings of the Fourth International Conference on Establishment Surveys (ICES-4), Montreal, Canada, June 11-14, 2012. Available at: http://www.amstat.org/meetings/ices/2012/ papers/302289.pdf (accessed June 2017).

Lorenc, B., M. Bavdaž, D. Giesen, R. Seljak, and V. Torres van Grinsven. 2012. "Businesses as Users of Official Statistics." In Proceedings of the Fourth International Conference on Establishment Surveys (ICES-4), Montreal, Canada, June 11-14, 2012. Available at: http://www.amstat.org/meetings/ices/2012/papers/302173.pdf (accessed June 2017).

Lorenc, B., W. Kloek, L. Abrahamson, and S. Eckman. 2013. “An Analysis of Business Response Burden and Response Behaviour Using a Register of Data Provision.” In Proceedings of the NTTS - Conferences on New Techniques and Technologies for Statistics. Brussels, 5-7 March 2013. Available at: https://ec.europa.eu/eurostat/cros/ system/files/NTTS2013fullPaper_121.pdf (accessed June 2017).

McCarthy, J.S., D.G. Beckler, and S.M. Qualey. 2006. “An Analysis of the Relationship Between Survey Burden and Nonresponse: If We Bother Them More, Are They Less Cooperative?" Journal of Official Statistics 22: 97-112. Available at: http://www.jos. nu/Articles/abstract.asp?article=221097 (accessed June 2017).

Rainer, N. 2008. "Measuring response burden under EU-context: Some principles for a management tool at the EU-level." Paper presented at the 94th Directors-General of the National Statistical Institutes (DGINS) Conference. Vilnius, September 25-26, 2008. Available at: http://ec.europa.eu/eurostat/documents/1001617/4411693/ O-2-AUSTRIA-MEASURING.pdf (accessed June 2017). 
Seens, D. 2013. SME Regulatory Compliance Cost Report September 2013. Results from the 2011 Statistics Canada Survey of Regulatory Compliance Costs. Statistics Canada: Ottawa. Available at: http://www.reducingpaperburden.gc.ca/eic/site/pbri-iafp.nsf/ vwapj/09-2013_eng.pdf/\$file/09-2013_eng.pdf (accessed June 2017).

Smeets, M. and H.J. Boonstra. 2017. "Sample Coordination of Business Surveys at Statistics Netherlands." Paper presented at the European Establishment Statistics Workshop EESW 2017, August 30-September 1, 2017, Southampton, UK. Available at: https://statswiki.unece.org/display/ENBES/EESW17+Programme?preview=/13 2219391/142442854/EESW17PaperMJESmeets.pdf (accessed October 2017).

Snijkers, G. and J. Jones. 2013. "Business Survey Communication." In Designing and Conducting Business Surveys, edited by G. Snijkers, G. Haraldsen, J. Jones, and D. Willimack, 359-430. Wiley: Hoboken, New Jersey. Doi: https://doi.org/ 10.1002/9781118447895.ch09.

United Nations. 2014. Fundamental Principles of Official Statistics. Available at: http:// unstats.un.org/unsd/dnss/gp/FP-New-E.pdf (accessed June 2017).

U.S. Paperwork Reduction Act of 1995 (1980). United States Federal Law. Title 44, Section 35, United States Code. U.S. Government Printing Office, Washington, D.C. Available at: https://www.gpo.gov/fdsys/pkg/STATUTE-109/pdf/STATUTE-109Pg163.pdf (accessed June 2017).

Vella, M. 2016. "Business Respondent Advocacy at Statistics Canada: Where We've Been and Where We're Going?" Proceedings of the Fifth International Conference of Establishment Surveys, June 20-23, 2016. Geneva, Switzerland: American Statistical Association. Available at: http://ww2.amstat.org/meetings/ices/2016/proceedings/ 097_ices15Final00301.pdf (accessed June 2017).

Vennix, K. 2012. "The Treatment of Large Enterprise Groups Within Statistics Netherlands." In Proceedings of the Fourth International Conference on Establishment Surveys (ICES-IV), June 11-14, 2012, Montreal, Canada, 871-880. Alexandria, VA: American Statistical Association. Available at: http://www.amstat.org/meetings/ices/ 2012/papers/301992.pdf (accessed June 2017).

Willeboordse, A. 1997. "Minimizing Response Burden." In Handbook on Design and Implementation of Business Surveys, edited by A. Willeboordse, 111-118. Luxembourg: Eurostat. Available at: http://ec.europa.eu/eurostat/ramon/statmanuals/ files/Handbook\%20on\%20surveys.pdf (accessed June 2017).

Zwijnenburg, J. 2012. "Redesign of the System of Economic Statistics in the Netherlands." Paper presented at the European Conference on Quality in Official Statistics Q2012, 8 May - 1 June 2012, Athens, Greece. Available at: http://www. q2012.gr/articlefiles/sessions/14.2_Jorrit\%20Zwijnenburg_Redesign\%20of\%20 economic\%20statistics.pdf (accessed June 2017).

Received October 2016

Revised September 2017

Accepted October 2017 